Int. J. Electrochem. Sci., 11 (2016) 9987 - 9997

\title{
Development of Conducting Poly(o-Aminophenol) Film and its Capacitance Behavior
}

\author{
Mohamed A Ghanem ${ }^{1, \S, *}$, Gaber El-Enany ${ }^{2}$ \\ ${ }^{1}$ Electrochemistry Research Group, Chemistry Department, College of Science, King Saud University, \\ Riyadh 11451, Kingdom of Saudia Arabia \\ ${ }^{2}$ Science \& Math Department, Faculty of Engineering, Port-Said University, Port Said, Egypt. \\ ${ }^{\S}$ Permanent address: Faculty of Petroleum and Mining Engineering, Suez University, Suez, Egypt. \\ *E-mail: $\underline{\text { mghanem@ksu.edu.sa }}$
}

doi: $10.20964 / 2016.12 .68$

Received: 20 July 2016 / Accepted: 12 October 2016 / Published: 10 November 2016

Electroactive and conducting poly(o-Aminophenol) POAP film is prepared firstly via chemical oxidation of o-aminophenol using ammonium persulfate in neutral medium followed by an electrochemical activation in $\mathrm{H}_{2} \mathrm{SO}_{4}$ solution. The redox processes and super capacitive behavior of the electroactive POAP polymer film were studied using cyclic voltammetry (CV) and electrochemical impedance spectroscopy (EIS). The electrochemical characterization of the activated polymer film shows the presence of distinctive redox sites which is active and stable up to overpotential of $0.8 \mathrm{~V}$ vs SCE. The EIS analysis displays the specific capacity of the activated POAP polymer film reaches up to $280 \mathrm{Fg}^{-1}$.

Keywords: Poly (o-Aminophenol), chemical oxidation, electrochemical impedance spectroscopy

\section{$\underline{\text { FULL TEXT }}$}

(C) 2016 The Authors. Published by ESG (www.electrochemsci.org). This article is an open access article distributed under the terms and conditions of the Creative Commons Attribution license (http://creativecommons.org/licenses/by/4.0/). 